\title{
Heinz Body to Erythrocyte Ratio Measurement
}

National Cancer Institute

\section{Source}

National Cancer Institute. Heinz Body to Erythrocyte Ratio Measurement. NCI

Thesaurus. Code C111206.

The determination of the ratio of the erythrocytes that contain heinz bodies compared to total erythrocytes present in a sample. The measurement may be expressed as a ratio or percentage. 